\title{
Caracterización de la CERÁMICA DE la FASE Ychsma Medio del sitio de Armatambo, Costa Central de Perú
}

Iván Falconí*

\section{Resumen}

Este trabajo trata del estilo cerámico Ychsma en cuanto se refiere a la fase Ychsma Medio, tal como lo define el Proyecto Arqueológico Armatambo. Las investigaciones sobre este estilo cerámico han estado concentradas en definir la secuencia cerámica, sin conceder mayor atención a precisar las características específicas de cada una de sus fases. Este es un intento por detallar la Fase Ychsma Medio, concentrándose en aspectos morfológicos, decorativos y productivos que permita reconocer mejor sus características.

\section{Palabras clave}

Intermedio Tardío, cerámica Ychsma Medio, Armatambo.

\begin{abstract}
This work deals with the ceramic style Ychsma as soon as it talks about the Middle Ychsma phase, as it defines the Archaeological Project Armatambo. The investigations on this ceramic style have been concentrated in defining the ceramic sequence, without giving further attention to clarify the specific characteristics of each one of their phases. This is an attempt to detail the Middle Ychsma Phase, concentrating in morphologic, decorative and productive aspects that allow to recognize better their characteristics.
\end{abstract}

Keyword

Late Intermediate, Middle Ychsma ceramic, Armatambo.

* Director (e) del Monumento Arqueológico Chavín de Huántar. Correo electrónico: ivanf_j@yahoo.es 


\section{UBICACIÓN Y DESCRIPCIÓN DEL SITIO}

El conjunto arqueológico de Armatambo se encuentra ubicado en el distrito de Chorrillos, provincia de Lima. El terreno sobre el que se asienta es una planicie relativamente homogénea, con una ligera inclinación hacia el Este, mientras que al Oeste destaca la presencia del Morro Solar en cuyas faldas se encuentra el sitio arqueológico y desde donde se observa la parte Sur de la ciudad de Lima, los Pantanos de Villa y las islas Pachacamac.

La geomorfología del Morro Solar está marcada por una elevación rocosa que se alcanza una altura de $281 \mathrm{msnm}$. El Morro Solar tiene una extensión aproximada de $7.48 \mathrm{~km} 2$, corre de Sur a Norte, más o menos paralelo a la litoral e interponiéndose entre el Océano Pacífico y el sitio arqueológico que ocupa su ladera Este.

Armatambo se compone de un gran centro urbano de compleja disposición cuya dimensión original de fue mucho mayor de lo que actualmente se observa. Gracias a las fotografías aéreas
(SAN 1945), (Fig. 1), son visibles diversas unidades arquitectónicas, articuladas por una serie de caminos que conectan los diferentes sectores. Comprende la ocupación de un espacio amplio, con arquitectura basada en la construcción de grandes muros de tapia y adobes hechos en molde, formando grandes recintos cuadrangulares y elevaciones macizas a partir de muros de contención y rellenos. Son destacables dos monumentos de carácter piramidal que sobresalen en altura y volumen con respecto a otros edificios, tales como Huaca Los Laureles y la Huaca Cruz de Armatambo. Excavaciones realizadas en diferentes épocas han ofrecido diversos elementos culturales, destacándose su abundante alfarería y contextos funerarios. La cronología asignada para este sitio arqueológico es atribuible a los periodos tardíos de la Costa Central, entre ellos el periodo Ychsma (1,000-1,470 d.C.) y el periodo Inca (1,470-1,532 d.C.); detectándose también, ocupaciones pertenecientes al periodo Colonial.

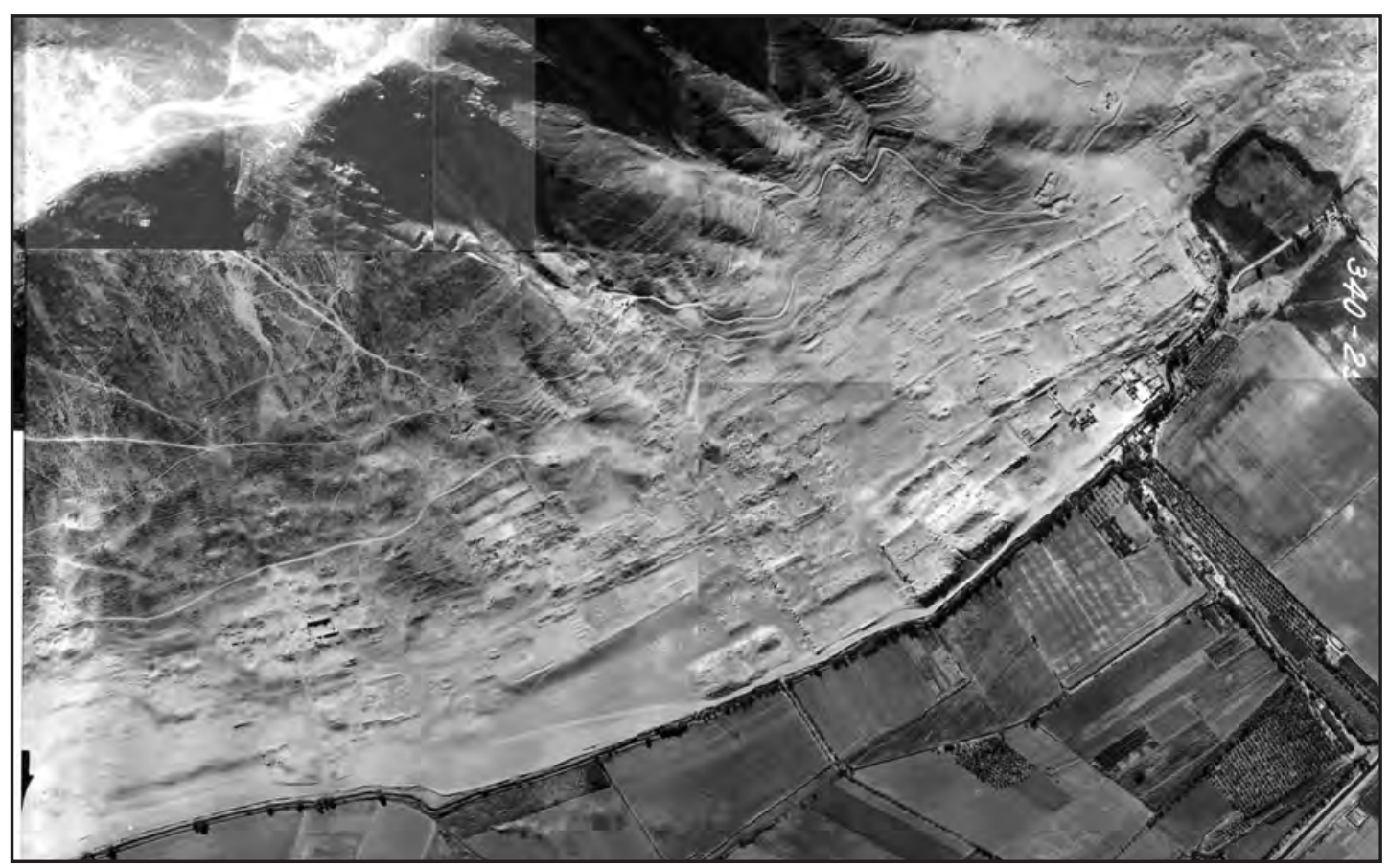

Figura 1. Fotografía aérea de Armatambo. SAN 1946. 
Armatambo se encuentra en proceso de destrucción. Desde la década de 1960 se han asentado diversos pueblos jóvenes que amenazan con destruirlo. Actualmente, el sitio arqueológico se encuentra totalmente circundado por las áreas de vivienda de la actual trama urbana que carece de los servicios de agua, desagüe, vías y veredas; el área de estudio está ocupada en el presente ocupado por los asentamientos humanos "San Pedro" y "22 de Octubre", los que se superponen al Conjunto Arqueológico de Armatambo, el mismo que se encuentra cubierto de tierra, arena eólica, desmonte de construcción y basura moderna, este crecimiento caótico de la ciudad ha desnaturalizado el sitio arqueológico, superponiéndose a él a modo de múltiples agrupaciones de vivienda. Se han realizado diversas investigaciones en Armatambo, entro ellos figuran los aportes de Badelier, publicado por Hyslop y Mujica (1992), Salvin (1973), Tello (1999), Bazán (1990), Pérez (1997), Ruales, Tosso y Vallejo (1983) Díaz (2000; 2004b; 2005), Díaz y Vallejo (2002; 2003)

\section{Planteamiento de la investigación}

La Costa Central ha sido escenario del desarrollo de uno de mayores centros religiosos prehispánicos, en efecto, el sitio de Pachacamac ha jugado un rol importante en la arqueología peruana, pues allí se inician los primeros trabajos de arqueología científica que permitieron a Uhle (1903) establecer la primera secuencia relativa de cerámica. Este hecho dio impulso a investigadores posteriores que realizaron trabajos similares en diversas partes de los Andes Centrales. Sin embargo, los estudios en la Costa Central, específicamente en los valles de Rímac y Lurín para los periodos tardíos no recibieron el mismo interés y los avances en la caracterización arqueológica de este periodo se han visto demorados.

Uno de los primeros en abordar el tema de la ocupación pre Inca en Lima fue Villar Cór- dova, quien planteó la tesis de la invasión de la Costa Central por grupos serranos acuñando el término Huancho para la cerámica tardía de los valles de Lima (Villar, 1935). El término Huancho dominó por mucho tiempo la forma de identificar a las poblaciones de los valles limeños.

Louis Stumer excavó en 1952 en Pedreros. Encontró una cerámica sencilla, pesada y decorada de manera burda, con simples rayas blancas (Stumer, 1954), igualmente la llamó Huancho, pero ésta no correspondía con la descripción hecha por Villar. Sin embargo, el término Huancho se continuó usando con el impulso de Iriarte Brenner (1960) que le agregó al estilo un tipo de decoración con serpiente ondulante.

María Rostworowski (1977, 1978, 1999), a partir del estudio de documentación colonial, ha identificando a Armatambo como uno de los principales asentamientos del valle del Rímac durante el Periodo Intermedio Tardío; a partir de sus investigaciones señala a que las antiguas poblaciones de los valles de Rímac y Lurín les corresponde el nombre Ychsma, esta posición fue reafirmada por los trabajos los trabajos arqueológicos de Jiménez Borja (1978) y Alberto Bueno (1982) quienes establecieron el uso de este nombre para la cultura de dichos valles.

La primera síntesis de la cerámica Ychsma la realizó Francisco Bazán para su tesis de licenciatura en 1990. Trabajo en el cuál hace una fuerte crítica al término Huancho y asigna el nombre de Ychsma al estilo cerámico dominante en la región después del Horizonte Medio.

En la secuencia de Francisco Bazán se distinguen tres fases: Inicial, Medio y Tardío, con una entidad cerámica separada y presente en todas las fases, llamada Ychsma Fitomorfo, mientras que otra denominada Tricolor Geométrico acompaña al Inicial y al Medio. En 1998, Régulo Franco presenta cuadros cronológicos, situando al estilo Ychsma en el Intermedio Tardío con una temporalidad posterior a $1050 \mathrm{~d}$. C. 
Y definiendo el estilo Ychsma en tres fases.

Posteriormente, trabajos de Paredes y Ramos (1994) en el sitio de Las Palmas y Díaz y Vallejo (2005) con material de contextos funerarios de Armatambo han permitido segregar las particularidades de las fases Media y Tardía. En efecto, el cuadro cronológico de Díaz y Vallejo (2002) establece una fase media distinguida de la Tardía por no estar asociada a elementos Inca ni a otros elementos que suelen asociarse a estos. Así logran realizar no sólo una tipología del cuerpo cerámico, sino que logran un avance en la caracterización de contextos funerarios y arquitectura asociada a cada fase. (Díaz y Vallejo, 2002; Díaz 2004a; Díaz 2004b; Díaz 2005).

En 2004 Vallejo publica su propuesta de secuencia cerámica Ychsma estableciendo tres fases cronológicas: Ychsma Temprano, que se inicia a finales del Horizonte Medio 4; Ychsma Medio, donde se notan cambios sustanciales con respecto a la fase anterior, adquiriendo sus formás clásicas; Ychsma Tardío el cual se asocia a la presencia Inca.

Por tanto la cerámica Ychsma está siendo mejor entendida y definida por el aporte de las diversas investigaciones. Sin embargo, un punto importante que aún queda por emprender, es el comportamiento del estilo dentro de cada fase de la secuencia, caracterizando detenidamente las formas, decoración y uso en un momento específico; esta necesidad se acentúa al observar que los autores suelen introducir nuevos tipos, basados en la observación parcial de la cerámica cuando en realidad se trata un rasgo de la variabilidad propia del estilo. Este factor es entendido por Feltham y Eeckhout (2005) quienes están realizando avances para la fase Tardía en Pachacamac.

Esta situación exige que se aborde el tema buscando precisar sus características específicas en cada una de sus fases, de tal forma que permita definir la pertinencia del funcionamiento de estas secuencias, condición necesaria para lo- grar la identificación precisa de otras expresiones de la cultura material Ychsma en Armatambo.

La Fase Media se define como la expresión clásica de lo Ychsma, por lo que una catalogación puntualizada de los rasgos y comportamiento del estilo en esta fase podría brindar aportes respecto a la demarcación precisa de la fase, para posteriormente extenderse a los demás componentes de la cultura buscando avanzar en el entendimiento desarrollo cultural Ychsma durante Intermedio Tardío en el valle del Rimac. Es evidente que debido a las variantes observadas en la cultura material de los diferentes sitios del valle de Lima, no es posible hacer generalizaciones para todo el área Ychsma a partir de un sitio, pero el inicio de este trabajo puede permitir aportar información detallada necesaria para precisar cuales son los elementos culturales que caracterizan las poblaciones locales antes de la ocupación Inca.

Para la presente investigación se aborda el estudio de la fase Ychsma Medio a partir de la definición publicada por Vallejo (2005) y dentro del marco del Proyecto Arqueológico Armatambo dirigido por Luisa Díaz. Los objetivos de nuestro trabajo comprenden: Estudiar los elementos y procesos productivos de la cerámica en la fase Ychsma medio; y, establecer un catálogo de formas apara la fase Ychsma Medio.

Para ello se analizó un total de 507 fragmentos diagnósticos de material cerámico recuperado de un basural arqueológico sin asociación arquitectónica (sector II, 22 de Octubre), durante las excavaciones realizadas en el año 2003 por el Proyecto Arqueológico Armatambo. El sector se ubica en la periferia Sur del antiguo asentamiento de Armatambo, en un terreno de suave pendiente.

\section{EXCAVACIONES ARQUEOLÓGICAS}

Las excavaciones arqueológicas tuvieron lugar en el sector II, área que actualmente es ocupada por el A.A.H.H. 22 de Octubre, las unida- 
des se ubicaron en las calles del asentamiento, realizándose hasta 8 unidades de excavación de diversas dimensiones, con profundidades que alcanzaron $3.50 \mathrm{~m}$ (Díaz, 2004). El material analizado para esta investigación provino de la Unidad 1, donde se identificaron restos arqueológicos de la fase Ychsma Medio.

\section{ESTRATIGRAFÍA UNIDAD 1}

Capa A: Es un relleno semi compacto de 20 a $30 \mathrm{~cm}$ de espesor, coloración gris oscuro, con material de desmonte y basura moderna.

Capa B: Tierra suelta de color gris-marrón oscuro y de 20 a $40 \mathrm{~cm}$ de espesor. Estrato arqueológico compuesto por una mezcla de cascajillo, arena, piedras pequeñas angulosas, fragmentos de cerámica y restos óseos animales.

Capa C: Tierra suelta de color beige, con un espesor de 50 a $70 \mathrm{~cm}$. Corresponde a un basural arqueológico. El estrato presenta una mezcla de arena con piedras pequeñas angulosas propias del cerro, abundante fragmentería cerámica, algunos restos de animales así como restos vegetales.

Capa D: Presenta un espesor de 20 a $110 \mathrm{~cm}$, es una mezcla de arena con piedras pequeñas angulosas propias del cerro. Presencia alternada de pocos fragmentos de cerámica y algunos restos óseos humanos sueltos. Algunos contextos funerarios intruyen esta capa.

Capa E: Estrato natural compuesto de arena suelta de grano fino acumulada por acarreo eólico. Su espesor es de 20 a $60 \mathrm{~cm}$ y es de color beige. Algunos contextos funerarios intruyen esta capa.

Capa F: Es en estrato natural compuesto por arcilla arenosa de proveniencia pluvial. Tiene un espesor de 10 a $15 \mathrm{~cm}$.
No se encontró material cultural.

Capa G: Formación rocosa correspondiente a la base del cerro, representa el final de la excavación en la unidad.

\section{DESCRIPCIÓN DE PASTAS}

La observación de las pastas se ha realizado con la ayuda de un Microscopio Stereo XTL500, facilitado por la Escuela de Arqueología de la Universidad San Marcos, utilizando un aumento de X-20. La colección de cerámica presenta una restringida variedad de pastas, distinguiéndose especialmente el uso de cuarzo como temperante. La base de la clasificación fue la clase de temperante dominante y su dispersión dentro de la pasta.

Pasta A: Pasta de color anaranjado, de textura granular. Predominan las inclusiones de granos de forma sub-angular de color negro mate y el cuarzo lechoso. Presencia de partículas pequeñas de calcita, con algunas partículas más grandes de hasta $3 \mathrm{~mm}$ Distribución homogénea.

Pasta B: Pasta de color anaranjado, de textura compacta. El elemento más abundante son los granos de color negro mate y forma sub-angular, las partículas de cuarzo lechoso están presentes pero en reducidas cantidades, la calcita es escasa.

Pasta C: Pasta de color anaranjado. Denota gran concentración de granos grandes, de forma irregular y con lados angulosos pero con distribución homogénea. Las inclusiones de partículas de cuarzo son pequeñas y escasas.

Pasta D: Pasta de color anaranjado rojizo, presenta como temperantes arena fina, poca cantidad de granos de calcita de perfil redondeado y tamaño variable y un temperante laminar de color gris azulado que en algunos casos llega a tener hasta $5 \mathrm{~mm}$. 


\begin{tabular}{|c|c|c|c|c|c|}
\hline & Pasta A & Pasta B & Pasta C & Pasta D & Pasta E \\
\hline Ollas & $\mathrm{X}$ & $\mathrm{X}$ & $\mathrm{X}$ & $\mathrm{X}$ & $\mathrm{X}$ \\
\hline Cántaros & $\mathrm{X}$ & $\mathrm{X}$ & $\mathrm{X}$ & & \\
\hline Tinajas & $\mathrm{X}$ & $\mathrm{X}$ & $\mathrm{X}$ & $\mathrm{X}$ & \\
\hline Botellas & & $\mathrm{X}$ & $\mathrm{X}$ & & \\
\hline Miniaturas & & $\mathrm{X}$ & & & \\
\hline
\end{tabular}

Figura 2. Distribución de los tipos de pasta con relación a las formas cerámicas.

Pasta E: Pasta de color anaranjado, que presenta mayormente arena fina de perfiles angulosos distribuidos de forma homogénea, con algunas inclusiones de calcita de regular tamaño, así como piedrecillas de sub-redondeadas de hasta $3 \mathrm{~mm}$.

Las pastas identificadas se presentan indistintamente en las diferentes formás cerámicas sobre todo la pasta $\mathrm{B}$, que se utiliza para elaborar todo tipo de vasijas, mientras que la pasta $\mathrm{C}$ es específica para ollas y tinajas.

\section{ClasificACIÓN Y DESCRIPCIÓN DE FORMÁS CERÁ- MICAS}

La colección de cerámica recogida sirvió para elaborar un catálogo de forms, agrupando aquellas de morfología similar para formar grupos reconocibles. Los rasgos cerámicos a considerar son: Forma (función, uso), Estilo (decoración, acabado) y Producción (pastas, cocción) estimando luego los rangos de popularidad de estos rasgos.

La siguiente descripción se basa en el análisis de un total de 507 fragmentos diagnósticos que conforman el 100\% de los fragmentos. La clasificación se realizó considerando aspectos morfológicos, permitiendo aislar 59 formás con sus respectivas variantes agrupados en 5 conjuntos denominados Ollas, Cántaros, Tinajas, Botellas y Miniaturas.

\section{Ollas}

Forma 1

Olla con cuello expandido, borde directo, labio adelgazado y redondeado. Se suele observar un adelgazamiento en el punto de unión del cuello con el cuerpo. Las asas son tubulares, no estructurales, se les coloca uniendo el cuerpo con la parte media o superior del cuello. Es la forma más numerosa con 91 fragmentos. Las pastas utilizadas son $\mathrm{A}$ y $\mathrm{B}$, mientras que la cocción es mayormente oxidante, pero con algunos fragmentos incompletos. La decoración se realiza aplicando pintura crema en el labio y el cuello; otros diseños algo más elaborados se realizan trazando líneas negras sobre pintura crema con una previa capa guinda. Otro tipo de decoración, que es la mñas a consiste en puntos incisos dentro de dos líneas paralelas incisas en la parte interna del cuello de la vasija. Muchos de los fragmentos encontrados mostraban restos de hollín. Esta forma es la más numerosa dentro del grupo estudiado. El diámetro de boca oscila entre 18 y $22 \mathrm{~cm}$. Se han reconocido dos variantes. (Fig. 3a).

Variante 1: En esta variante la pared interna del cuello es ligeramente oblongada para luego disminuir rápidamente formando un adelgazamiento del labio, mientras que el adelgazamiento de la unión con el cuerpo es más notorio. (Fig. 3b).

Variante 2: Se le encuentra con el labio más redondeado, el adelgazamiento en la unión con 
el cuerpo es casi imperceptible, y el grosor del cuerpo es menor que el del cuello. (Fig. 3c).

\section{Forma 2}

Olla con cuello expandido, borde directo y labio redondeado sin adelgazamiento en el labio ni en la unión con el cuerpo, las asas son tubulares no estructurales, colocadas sobre el punto de inflexión del cuerpo, el cual es globular. Los diámetros de boca promedian los $20 \mathrm{~cm}$. La cocción es oxidante, elaborada en pasta A; sólo se encontraron 2 especimenes de esta forma, sin variantes. (Fig. 4).

\section{Forma 3}

Olla de cuello expandido y labio muy adelgazado, el cuello comienza con un promedio de $7 \mathrm{~mm}$. Adelgazándose directamente hasta llegar a un punto más o menos afilado, También se observa en algunos especimenes, un adelgazamiento a modo de surco muy cerca del labio, y un surco muy notorio se forma en la unión del cuello con el cuerpo. Se han encontrado 34 fragmentos de esta forma con un promedio de boca de $22 \mathrm{~cm}$. Estos tiestos suelen estar quemados y se les elabora en pasta A y B. (Fig. 5a).

Variante 1: Se le observa con mayor grosor del cuello, el adelgazamiento en la pared externa del borde es más sutil, mientras que desaparece el surco de la unión con el cuerpo. (Fig. 5b).

\section{Forma 4}

Olla con cuello expandido, borde directo, labio adelgazado y afilado. El cuello forma un ligero arco hacia el interior de la vasija. Las pasta utilizada es B, y la cocción es oxidante, solo se encontró un fragmento de este tipo sin decoración. (Fig. 6 ).

\section{Forma 5}

Olla de cuello expandido, borde grueso y labio redondeado, la longitud del cuello es algo más corta y el ángulo de expansión varía ligeramente. La parte terminal del cuerpo es adelga- zada. Pasta utilizada es B y D. El tratamiento de superficie es alisado tosco con marcas horizontales. Las piezas decoradas tienen pintura crema en bandas. Número de fragmentos 10. (Fig. 7).

\section{Forma 6}

Olla de cuello expandido, borde directo y delgado, labio redondeado, la longitud del cuello es más corta y el ángulo de expansión también es menor. En la parte terminal del cuerpo hay un ligero engrosamiento aunque disminuye rápidamente al unirse con el cuello. Pasta utilizada es B y C. La superficie tiene un tratamiento de alisado tosco con marcas horizontales. Las piezas decoradas tienen pintura crema en bandas en la parte interna y/o externa del labio. El promedio de diámetro de boca es 18, con 26 fragmentos recuperados. (Fig. 8).

\section{Forma 7}

Se trata de una olla con cuello expandido, borde directo, labio adelgazado y redondeado. El cuello tiene mayor longitud que otras ollas y las paredes son delgadas. Tiene un adelgazamiento en el punto de unión del cuello con el cuerpo, y otro más notorio en la pared externa del borde, muy cerca del labio, Las pastas utilizadas B y C, la cocción es mayormente oxidante, pero con algunos fragmentos incompletos. La decoración se realiza aplicando pintura crema en el labio y el cuello,así como negro y blanco sobre guinda. Algunos fragmentos encontrados mostraban restos de hollín. Los diámetros de boca oscilan entre lo 16 y $20 \mathrm{~cm}$. Número de fragmentos: 19 . (Fig. 9a).

Variante 1: Esta variante presenta un engrosamiento en la pared externa del borde, cerca del labio, para adelgazarse rápidamente en el labio. (Fig. 9b).

\section{Forma 8}

Olla de cuello expandido y labio muy adelgazado, el cuello comienza con mayor grosor adelgazándose directamente hasta llegar a pre- 
sentar el labio afilado, No se observa el adelgazamiento común en la unión con el cuerpo. Se encontraron 20 fragmentos con diámetros promedios de $20 \mathrm{~cm}$. (Fig. 10).

\section{Forma 9}

Olla cerrada de cuello expandido, borde grueso y directo, labio redondeado, la longitud del cuello es corta y forma un ligero arco hacia el interior. La parte terminal del cuerpo es adelgazada, así como en el cuello, formando una especie de surco. La Pasta utilizada es B y D. El tratamiento de superficie es alisado tosco con marcas horizontales. El promedio de diámetro es 18 $\mathrm{cm}$. con 19 fragmentos encontrados. (Fig. 11a).

Variante 1: Presenta el labio más redondeado, mientras que el cuello es ligeramente más largo. (Fig. 11b).

\section{Forma 10}

Olla cerrada de cuello ligeramente evertido, elaborada en pasta C. La superficie es alisada dejando incisiones o estrías horizontales en el cuello. Presenta un notorio adelgazamiento en el borde exterior, cerca del labio, el mismo que a veces es biselado en su lado interno; el cuello no es muy largo, Las bocas promedian los $16 \mathrm{~cm}$. Se distinguen 29 fragmentos de este tipo de los cuales varios muestran manchas de hollín. (Fig. 12a).

Variante 1: Tiene la unión con el cuello con el cuerpo más delgada para ir aumentando su espesor a medida que se acerca al labio, para adelgazarse rápidamente y terminar con un labio redondeado. (Fig. 12b).

Variante 2: Esta variante se distingue por tener un mayor ángulo de expansión del cuello y no presenta adelgazamiento en la unión del cuello y el cuerpo. (Fig. 12c).

Variante 3: Esta tiene un cuello más corto que las demás variantes y el labio interno es ligeramente biselado. (Fig. 12d).

\section{Forma 11}

Olla con cuello muy expandido, labio adelgazado que puede ser redondeado o anguloso dependiendo de la variante. Las asas son tubulares, no estructurales, se las coloca uniendo el cuerpo con el tercio superior del cuello. La pasta de fabricación es A, mientras que la cocción es oxidante, pero hay fragmentos de cocción incompleta. La decoración se realiza aplicando pintura crema en líneas, sobre el labio y el cuello. Se encontraron 14 fragmentos, la mayoría con restos de hollín, con un promedio de boca de $20 \mathrm{~cm}$. (Fig. 13a).

Variante 1: Esta variante presenta el labio anguloso con un ligero adelgazamiento en la pared externa del borde. (Fig. 13b).

\section{Forma 12}

Olla con cuello muy expandido, borde directo y muy grueso, labio recto con una ligera extensión en el lado externo. El tratamiento de superficie es alisado tosco formando líneas horizontales sutiles en la pared externa del cuello. La cocción es oxidante con una coloración algo más oscurecida. La pasta utilizada es $\mathrm{E}$, se identificó 14 fragmentos de este tipo, con un diámetro de $24 \mathrm{~cm}$. (Fig. 14).

\section{Forma 13}

Olla de cuello corto, evertido. Borde grueso y labio redondeado. Presenta un fuerte ángulo de inflexión del cuello con el cuerpo. La superficie es alisada y la cocción oxidante. La pasta utilizada es B. La decoración se restringe a pintura crema sobre el labio interno y externo, además de un ejemplo de punteado en zona; se encontraron fragmentos con hollín. El diámetro promedio es $18 \mathrm{~cm}$. (Fig. 15).

\section{Forma 14}

Olla de cuerpo globular de cuello convexo y labio redondeado, el cual puede estar levemente evertido. Elaborada en pasta B y cocción 


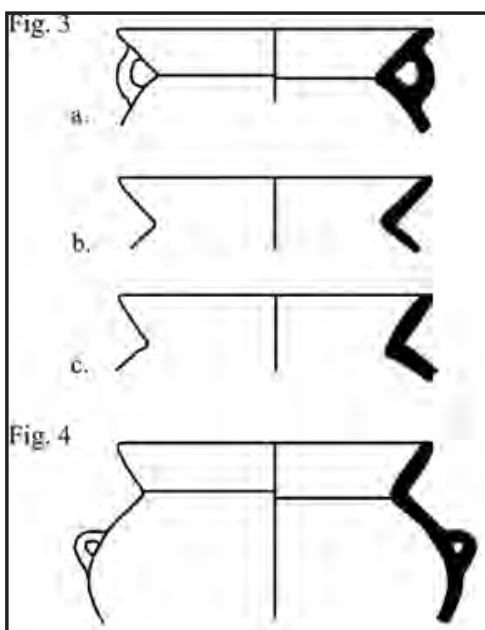

Fig. 5

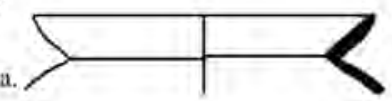

b.

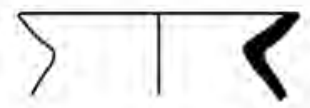

Fig. 6

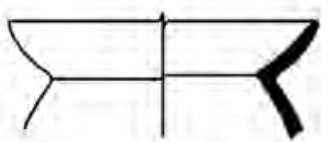

Fig. 7

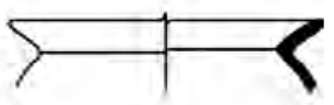

Fig. 8

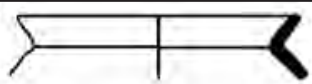

Fig. 9
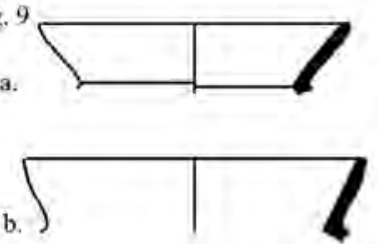

Fig. 10

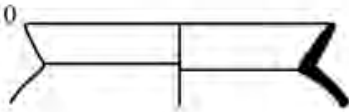

Fig. 11

ก.

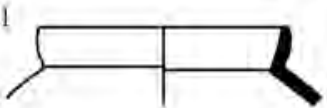

b.

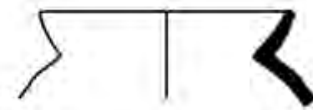

Fig. 12

a.

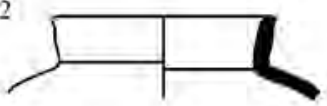

b.

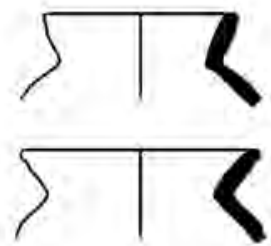

Fig. 13

a.

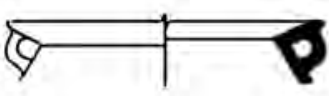

b.

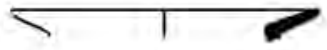

Fig. 14

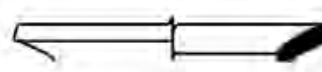

Fig, 15

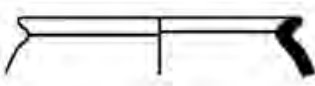

Fig. 16

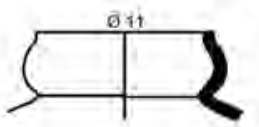

b.

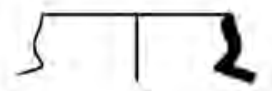

c,

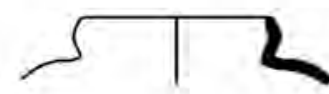

Fig. 17
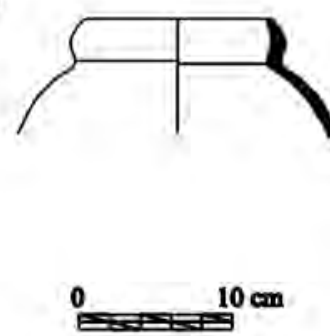

oxidante con acabado de alisado. El diámetro de la boca se sitúa entre los 11 y $16 \mathrm{~cm}$. La decoración, cuando está presente, es común a la cerámica de esta fase, es decir, crema aplicada de forma descuidada en el labio o le tercio inferior del cuello. (Fig. 16a).

Variante 1: Tiene el cuello menos pronunciado y labio redondeado (Fig. 16b).

Variante 2: Esta variante tiene el labio bastante adelgazado y hacia adentro. (Fig. 16c).

\section{Forma 15}

Olla de cuello compuesto y labio adelgaza- do. El borde es engrosado pero va adelgazándose conforme se dirige hacia el labio, por lo que la parte más gruesa se presenta en la unión del cuello con el cuerpo. Se utiliza la pasta B; sólo se encontró un ejemplar. (Fig. 17).

\section{CÁntaros}

\section{Forma 1}

Vasija cerrada con cuello levemente expandido, labio adelgazado y redondeado, la pared interna del cuello suele estar adelgazada en su parte media. Las asas son tubulares y no estructurales, unen el cuerpo con la parte media del 
cuello. La superficie es alisada dejando marcas horizontales. Se le elabora en pasta C y B. Se decoró aplicando pintura crema en el labio interior y exterior y en el tercio inferior del cuello, se identificó un fragmento con engobe guinda. Se encontraron 26 fragmentos, con un promedio de diámetro de boca de $12 \mathrm{~cm}$. (Fig. 18a).

Variante 1: Esta variante presenta menor ángulo de expansión del cuello, las paredes del cuerpo son más delgadas y las asas son redondeadas (Fig. 18b).

Variante 2: El ángulo de expansión del cuello es menor que en la variante 1 , el cuello es ligeramente arqueado y el labio más evertido. (Fig. 18c).

Variante 3: Presenta adelgazamiento en la parte interna y externa del borde y labio delgado y redondeado. (Fig. 18d).

\section{Forma 2}

Cántaro de cuello evertido, labio adelgazado hacia adentro, redondeado. Se la elabora en pasta $B$, tratando la superficie con alisado tosco que deja marcas en el cuello. Esta forma presenta asas verticales que unen el cuerpo con el cuello. Los diámetros de boca promedian los 14 cm encontrándose 16 ejemplares. Se le decora con pintura crema en el labio interior y exterior. (Fig. 19).

\section{Forma 3}

Este es un cántaro de cuello evertido, borde directo, labio adelgazado hacia afuera, redondeado. En la parte interna de la unión del cuello con el cuerpo se observa un severo adelgazamiento que llega a formar un arco pronunciado. Se la elabora en pasta B, tratando la superficie con alisado tosco que deja marcas horizontales en el cuello. Las bocas tienen un diámetro de $10 \mathrm{~cm}$. Se encontraron dos fragmentos de es te tipo. (Fig. 20).

\section{Forma 4}

Vasija cerrada con cuello vertical y ligeramente disminuido en la parte central, el labio es adelgazado y redondeado, La superficie es alisada dejando marcas horizontales. Se le elabora en pasta B y C. La decoración se realiza aplicando pintura crema en el labio interior y exterior. Se encontraron 6 fragmentos con promedio de 14 centímetros de ancho de boca. (Fig. 21a).

Variante 1: Presenta un ligero adelgazamiento en la parte final del borde, muy cerca del labio el cual se encuentra evertido. (Fig. 21b).

\section{Forma 5}

Cántaro con cuello ligeramente evertido, borde grueso que va adelgazándose conforme se dirige al labio, el cual es adelgazado y puede ser algo evertido. Es común encontrar la parte inferior del cuello adelgazada, líneas horizontales formadas por alisado. La pasta utilizada es A y $\mathrm{C}$ y la cocción es oxidante, mientras que el diámetro de boca es $12 \mathrm{~cm}$. Se han encontrado 12 ejemplos, varios con evidencias de quema. (Fig. 22a).

Variante 1: esta variante presenta el labio redondeado y no se encuentra evertido. (Fig. 22b).

Variante 2: Labio entre angulosos y redondeado, además de estar ligeramente biselado en la parte interna. (Fig. 22c).

\section{Forma 6}

Se trata de un cántaro de cuello evertido, borde directo, labio adelgazado, redondeado que suele estar ligeramente evertido. Se la elabora en pasta B y C, el tratamiento de superficie es alisado tosco que deja marcas en el cuello. Los diámetros de boca promedian los 10 $\mathrm{cm}$. Se le decora con pintura crema en el labio interior y exterior. Se encontraron 4 ejemplares. (Fig. 23a). 


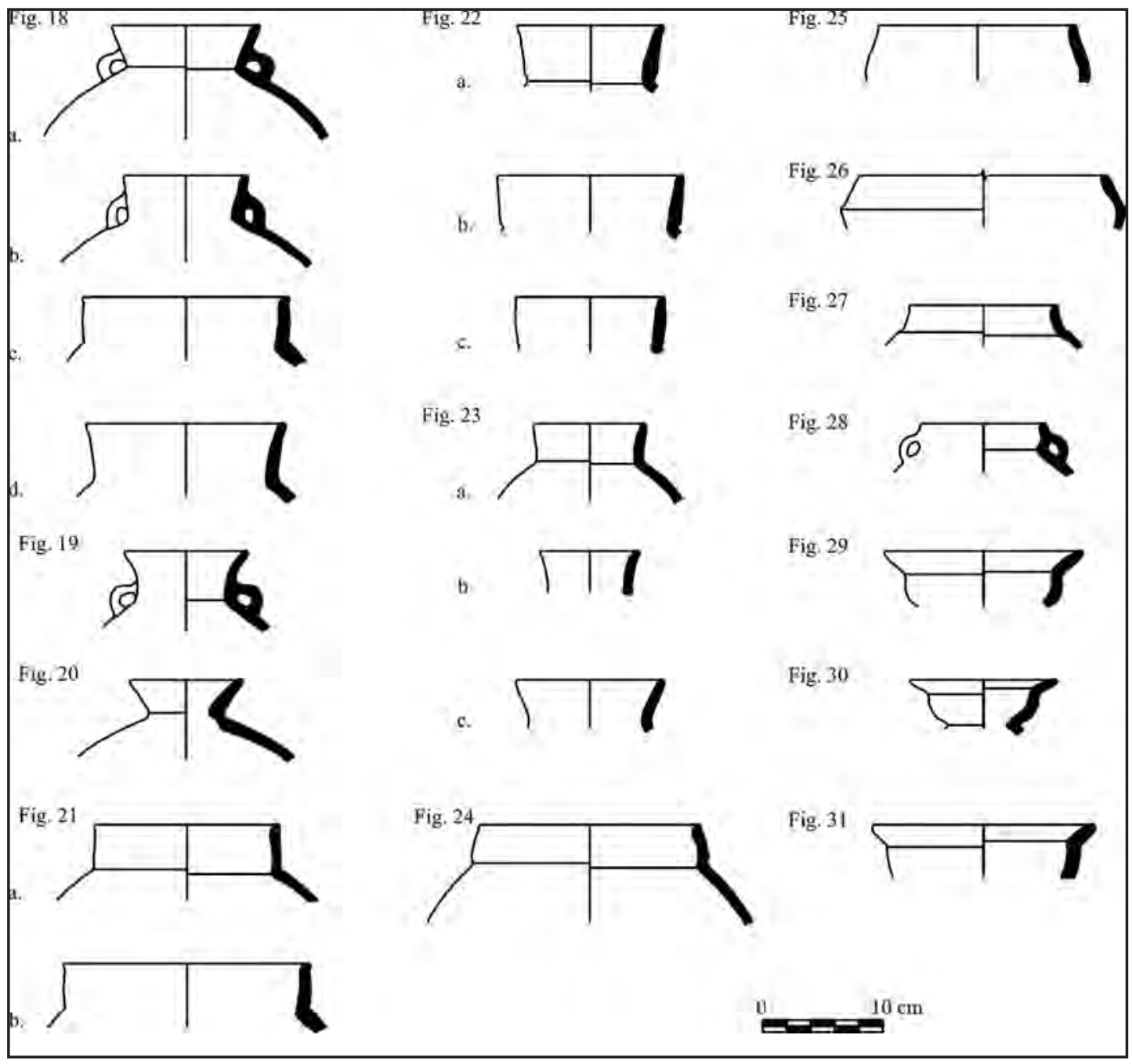

Variante 1: Se diferencia por tener el labio evertido. (Fig. 23b).

Variante 2: Esta variante muestra el cuello con mayor ángulo de expansión y labios redondeados. (Fig. 23c).

\section{Forma 7}

Vasija de cuello convergente, borde directo que forma un ligero arco hacia el interior; el labio es adelgazado, con un leve bisel en la parte interna, y someramente evertido. La unión del cuello y cuerpo está adelgazada. Es elaborada en pasta $B$ con cocción oxidante y superficie en alisado tosco. El diámetro es $17 \mathrm{~cm}$. Solo se encontró un fragmento de este tipo. (Fig. 24).

\section{Forma 8}

Cántaro de cuello convergente, borde directo y labio redondeado, con un leve adelgazamiento o bisel en la parte interna. La unión del cuello y cuerpo no se encuentra adelgazada. Forma elaborada en pasta A con cocción oxidante y superficie en alisado tosco. El diámetro del único espécimen reconocido es $16 \mathrm{~cm}$. (Fig. 25). 


\section{Forma 9}

Cántaro de cuello compuesto, el cual se inicia con una forma recta y expandida, para luego volverse convergente, formando un lado anguloso en la parte externa del punto de inflexión del cuello. El labio es redondeado, el tratamiento de superficie es alisado algo más cuidadoso que el común de los fragmentos. Forma elaborada en pasta A con cocción oxidante. Sólo se encontró un fragmento con diámetro de $24 \mathrm{~cm}$. (Fig. 26).

\section{Forma 10}

Vasija de cuello convergente, borde directo y labio adelgazado, con un leve bisel en la parte interna, mientras que el labio está someramente evertido. La unión del cuello y cuerpo puede estar adelgazada. Forma elaborada en pasta B con cocción oxidante y superficie en alisado tosco. El diámetro es de $12 \mathrm{~cm}$. Se encontró un fragmento. (Fig. 27).

\section{Forma 11}

Cuello compuesto, borde directo y labio adelgazado, el cual puede estar levemente evertido o estar biselado al interior. Presenta asa tubular aplicada que une la porción media del cuello con el cuerpo. Elaborada en pasta B y cocción oxidante con acabado de alisado. El diámetro de la boca se sitúa entre los 10 y 12 cm. La decoración, cuando está presente, es común a la cerámica de esta fase, es decir, crema aplicada de forma descuidada en el labio o le tercio inferior del cuello. Se encontraron 4 ejemplares. (Fig. 28).

\section{Forma 12}

Cántaro de cuello compuesto, borde directo y labio adelgazado evertido. La superficie es alisado tosco con cocción oxidante. La pasta utilizada es B. El diámetro de boca fluctúa entre 12 y 18 $\mathrm{cm}$. Cuando hay decoración se realiza con pin- tura crema, se encontraron 5 fragmentos. (Fig. 29).

\section{Forma 13}

Cántaro de cuello compuesto y labio adelgazado evertido. Se observa que el adelgazamiento de la unión del cuello y el cuerpo es más profundo que en otras formás. La superficie es alisado tosco con cocción oxidante. Se identificaron 5 ejemplares, donde se utilizó la pasta es A y B. El diámetro de boca fluctúa entre 18 y $20 \mathrm{~cm}$. Cuando hay decoración se realiza con pintura crema. (Fig. 30).

\section{Forma 14}

Cántaro de cuello evertido, borde directo y labio adelgazado redondeado. Las paredes son gruesas, la superficie es acabada con un alisado tosco, mientras que la cocción es oxidante. Se le elabora en pasta B. El promedio de diámetro de boca es $18 \mathrm{~cm}$. No se encontraron fragmentos decorados. (Fig. 31).

\section{Tinajas}

\section{Forma 1}

Tinaja de cuello recto, ligeramente adelgazado, labio redondeado o con bisel hacia el interior, también presenta un adelgazamiento en el borde exterior previo al labio, así como otro en la unión del cuello con el cuerpo. El alisado que se le realiza suele dejar marcas horizontales en el cuello y parte final del cuerpo. Cuando se le decora es con bandas de pintura crema de aplicación descuidada en el labio y el cuello. Se le fabrica en pasta B; la cocción es oxidante y los diámetros varían entre 20 y $26 \mathrm{~cm}$. (Fig. 32a).

Variante 1: Esta variante tiene el labio interno más biselado y un mayor adelgazamiento en el borde exterior. (Fig. 32b).

Variante 2: En este caso el labio es adelgazado la parte interna y redondeado. (Fig. 32c).

Variante 3: El borde es arqueado, con el 
labio evertido y biselado hacia el interior. (Fig. $32 d)$.

\section{Forma 2}

Tinaja con cuello convergente y redondeado, borde directo, labio recto y paredes delgadas. Se le aplica el alisado como tratamiento de superficie que en general es de acabado tosco. No se encontraron ejemplares decorados y la pasta utilizada es C. (Fig. 33a).

Variante 1: El ángulo convergente es menor y el labio anguloso. (Fig. 33b).

Variante 2: El labio se encuentra redondeado en su lado exterior y se observa un adelgazamiento entre el borde y el labio. (Fig. 33c).

Variante 3: Muestra el labio redondeado y adelgazamiento en la unión del labio con el borde. (Fig. 33d).

Variante 4: El ángulo de convergencia es mayor que en las otras variantes y labio redondeado. (Fig. 33e).

\section{Forma 3}

Tinaja de cuello ligeramente expandido labio redondeado y biselado hacia el interior, en el extremo del borde se realiza un adelgazamiento a modo de surco que corre horizontal en todo el diámetro del borde. Un adelgazamiento más marcado se encuentra en la unión del cuello y el cuerpo. Estas vasijas denotan huellas de su fabricación en modelado y las incisiones del alisado en el cuello y la parte superior del cuerpo. Su diámetro varía entre 24 y $28 \mathrm{~cm}$. Son elaboradas indistintamente en pastas B y D. (Fig. 34a).

Variante 1: El biselado del labio es mayor, y el adelgazamiento menor tanto en el labio como en el cuerpo. (Fig. 34b).

\section{Forma 4}

Tinaja con cuello ligeramente convergente y de paredes gruesas, labio redondeado, borde directo. Como en las demás formas, se observan marcas dejadas por el alisado con que fue traba- jada la superficie. El diámetro de la boca llega a los $40 \mathrm{~cm}$, ninguno de los tres ejemplares presenta decoración. La pasta que se utiliza para la fabricación es D. No se encontraron variantes. (Fig. 35).

\section{Forma 5}

Tinaja de cuello convergente, borde muy engrosado y recto, este va haciéndose más delgado conforme se acerca al cuerpo. La superficie es alisada y tosca, se le elabora en pasta $\mathrm{C}$ y es de cocción oxidante. El diámetro de la boca promedia los $28 \mathrm{~cm}$. La decoración consiste en aplicar bandas de pintura crema en la superficie interna y externa del labio. (Fig. 36a).

Variante 1: Presentan una elevación estructural similar a un chichón ubicada cerca del labio. El cuello es más convergente. (Fig. 36b).

\section{Forma 6}

Tinaja de cuello convergente con borde muy engrosado, el borde interno presenta un bisel ancho, la superficie es alisada y tosca, se le elabora en pasta $\mathrm{C}$ y es de cocción oxidante. El diámetro de la boca suele ser amplio, entre 24 y $28 \mathrm{~cm}$. Algunos tiestos presentan una elevación estructural similar a un chichón. La decoración consiste en aplicar bandas de pintura crema en la superficie interna y externa del labio. No se encontraron variantes. (Fig. 37).

\section{Forma 7}

Tinaja de cuello ligeramente expandido, labio adelgazado, en el extremo del borde se realiza un adelgazamiento a modo de surco que corre horizontal en todo el diámetro del borde. Un adelgazamiento más marcado se encuentra en la unión del cuello y el cuerpo. Se observan huellas de modelado en su fabricación. Mientras que el acabado de superficie deja incisiones suaves en el cuello y la parte superior del cuerpo. Se encontraron dos variantes. Su diámetro varía entre 24 y $28 \mathrm{~cm}$. Son elaborada indistin- 


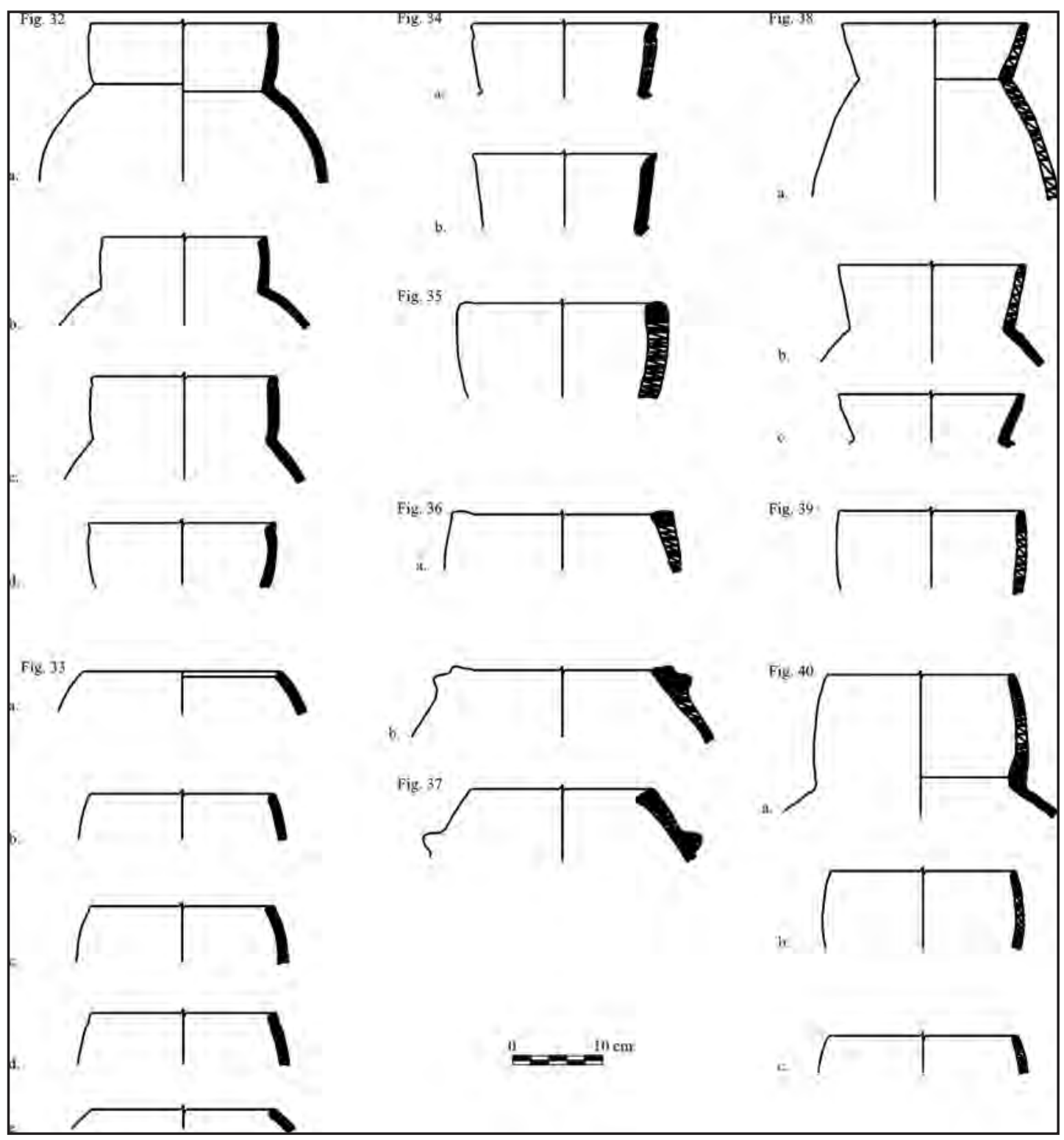

tamente en pastas B, D. (Fig. 38a).

Variante 1: El cuello es un poco más recto y el labio más redondeado. (Fig. 38b).

Variante 2: Presenta el cuello más corto y adelgazamiento del borde es más ancho. (Fig. 38c).

\section{Forma 8}

Esta tinaja presenta el cuello ligeramen- te divergente, labio biselado hacia el interior, borde directo. Muestra un adelgazamiento en la unión del cuello con el cuerpo. La superficie se ha acabado con la técnica del alisado; La decoración se expresa con líneas de pintura chorreada, ubicadas en la base del cuello, mientras que el promedio de diámetro de boca es $29 \mathrm{~cm}$ y la pasta utilizada es $\mathrm{C}$ y D. No se encontraron tiestos con huellas de uso. (Fig. 39). 


\section{Forma 9}

Tinaja de cuello largo y convergente, borde directo, labio adelgazado; en la base del cuello se observa un fuerte engrosamiento, pero este desaparece en unión con el cuerpo; además, son observables las huellas dejadas por su elaboración utilizando la técnica del modelado. La superficie presenta estrías producto del alisado tosco con que fue tratada. El diámetro de la boca promedia los $28 \mathrm{~cm}$. La pasta utilizada es C. Se encontraron dos variantes. (Ffig. 40a).

Variante 1: Esta variante no presenta el engrosamiento en la base del cuello. (Fig. 40b).

Variante 2: Se le observa con un mayor ángulo de convergencia y el labio algo más redondeado que en las demás variantes. (Fig. 40c).

\section{Forma 10}

Tinaja de cuello compuesto, borde engrosado, labio evertido y redondeado. El labio forma un ángulo de inflexión en la unión con el cuello, dándole un perfil aquillado. La pasta para la elaboración es A. cocción oxidante y superficie alisada. El diámetro de boca es $26 \mathrm{~cm}$. (Fig. 41a).

Variante 1: Presenta una protuberancia estructural en el cuello a modo de decoración. (Fig. 41b).

\section{Forma 11}

Tinaja de cuello divergente, borde directo y labio redondeado. La superficie es alisada dejando incisiones o estrías horizontales en el cuello. Como en los demás casos, la cocción es oxidante y el grosor de las paredes delgado. Las bocas promedian los $24 \mathrm{~cm}$. Varios especimenes muestran manchas de hollín. Son elaboradas indistintamente en pasta A, B y C. (Fig. 42a).

Variante 1: Es menos expandido, casi recto y de labio más redondeado. (Fig. 42b).

\section{Forma 12}

Vasija de cuello convergente y delgado, borde directo, labio adelgazado. Se observa las marcas horizontales dejadas por el alisado de la superficie. La cocción es oxidante, con pasta B y la decoración se realiza aplicándole pintura crema alrededor del labio y el cuello en la unión con cuerpo. El promedio e diámetro de boca 20 $\mathrm{cm}$. No se encontraron variantes. (Fig. 43).

\section{Forma 13}

Tinaja de cuello recto y engrosado en la parte superior, con un adelgazamiento en la unión con el borde a modo de surco que rodea todo el borde, mientras que se observa biselado en la parte interna. El cuello se adelgaza conforme se acerca al cuerpo, en cuya unión se forma un adelgazamiento a modo de surco, el cuerpo es más grueso que el cuello. La cocción es oxidante, y la superficie es alisada dejando marcas horizontales de este proceso. Para su elaboración se utiliza pasta B y C. El diámetro de boca es 24 $\mathrm{cm}$. No se encontraron variantes. (Fig. 44).

\section{Forma 14}

Vasija de cuello ligeramente divergente, el labio es adelgazado con un ligero bisel hacia el interior. La cocción es oxidante, mientras que el alisado es el acabado de superficie. La decoración se presenta con pintura crema aplicada en el labio externo y en la base del cuello Los diámetros de boca promedian los $28 \mathrm{~cm}$. y no encontraron variantes. Pasta B. (Fig. 45).

\section{Forma 15}

Tinaja de cuello ligeramente divergente y grueso, borde directo, labio adelgazado a partir de la pared externa del cuello. En algunos fragmentos se observa el adelgazamiento en la unión del cuello con el cuerpo. El acabado de superficie es alisado dejando estrías horizontales en el cuello. Se encontró seis ejemplares de este tipo, elaborado en pasta B. La decoración se realizó aplicando pintura crema en la base del 
cuello y en la parte terminal del cuerpo, mientras que el promedio de diámetro de boca es de $26 \mathrm{~cm}$. (Fig. 46).

\section{Forma 16}

Tinaja de cuello alargado, ligeramente expandido, borde directo, delgado y labio un poco evertido. En el punto de unión con el cuerpo presenta un ligero adelgazamiento. El alisado dejó líneas horizontales muy marcadas que se prolongan hasta $2 \mathrm{~cm}$. del cuerpo. Se utilizó la pasta B y la cocción es oxidante. No se encontraron tiestos decorados ni quemados. El diámetro promedio es de $28 \mathrm{~cm}$. (Fig. 47).

\section{Forma 17}

Tinaja de cuello convergente, el labio muestra una hendidura profunda en la parte central, está elaborada en pasta B y cocción oxidante. Se observan las estrías horizontales producto del alisado; el diámetro es de $30 \mathrm{~cm}$. (Fig. 48).

\section{Forma 18}

Tinaja de cuello alargado, ligeramente expandido, borde directo, delgado y labio recto, El alisado que se le aplica deja líneas horizontales muy marcadas que se prolongan hasta 2 $\mathrm{cm}$. del cuerpo. La pasta utilizada es B y C, la cocción es oxidante. No se encontraron tiestos decorados ni quemados. El diámetro promedio es de $26 \mathrm{~cm}$. (Fig. 49).

\section{Forma 19}

Tinaja de cuello grueso y corto, ligeramente evertido, borde directo y labio redondeado. Se le fabrica en pasta D. La cocción es oxidante, la superficie es toscamente alisada, notándose las inclusiones líticas que sobresalen a la pasta. No tiene decoración ni huellas de hollín. El diámetro de boca es $26 \mathrm{~cm}$. (Fig. 50).

\section{Forma 20}

Tinaja de cuello grueso, evertido, borde directo y labio biselado hacia fuera. Se le fabrica en pasta D. La cocción es oxidante, la superficie es toscamente alisada, notándose las inclusiones líticas que sobresalen a la pasta. No tiene decoración ni huellas de hollín. El diámetro de boca es $30 \mathrm{~cm}$. (Fig. 51).

\section{Forma 21}

Tinaja de cuello largo, expandido, borde directo y labio biselado hacia fuera. Tiesto de aspecto macizo, elaborado con pasta $\mathrm{D}$, el alisado de la superficie es muy tosco, la cocción es oxidante, sin decoración ni restos de hollín. El diámetro es de $28 \mathrm{~cm}$. (Fig. 52).

\section{Forma 22}

Tinaja de cuello evertido, engrosado en la parte baja, el labio es recto y grueso, está elaborada en pasta $\mathrm{B}$ y cocción oxidante. Se observan las estrías horizontales producto del alisado; el diámetro es de $42 \mathrm{~cm}$. No posee decoración, pero se encontró un fragmento con agujero en fila al lado de la rotura, posiblemente hechos par evitar que una rotura continúe hasta inhabilitar la vasija. (Fig. 53).

\section{Forma 23}

Vasija cerrada sin cuello, borde directo, labio recto con una pequeña elevación de intención decorativa, cuando tienen asas pueden ser horizontales o verticales de función decorativa. Se les fabrica en pasta C. La cocción es oxidante con alisado tosco, la decoración es con pintura crema chorreada, diseñando bandas en el labio y cerca de la boca, que suele tener un diámetro de más de $26 \mathrm{~cm}$. Se encontraron 28 fragmentos. (Fig. 54a).

Variante 1: Presenta menor elevación en la parte externa del labio y un surco decorativo al final del borde e inicio del labio. (Fig. 54b).

Variante 2: Esta variante tiene asas tubula- 


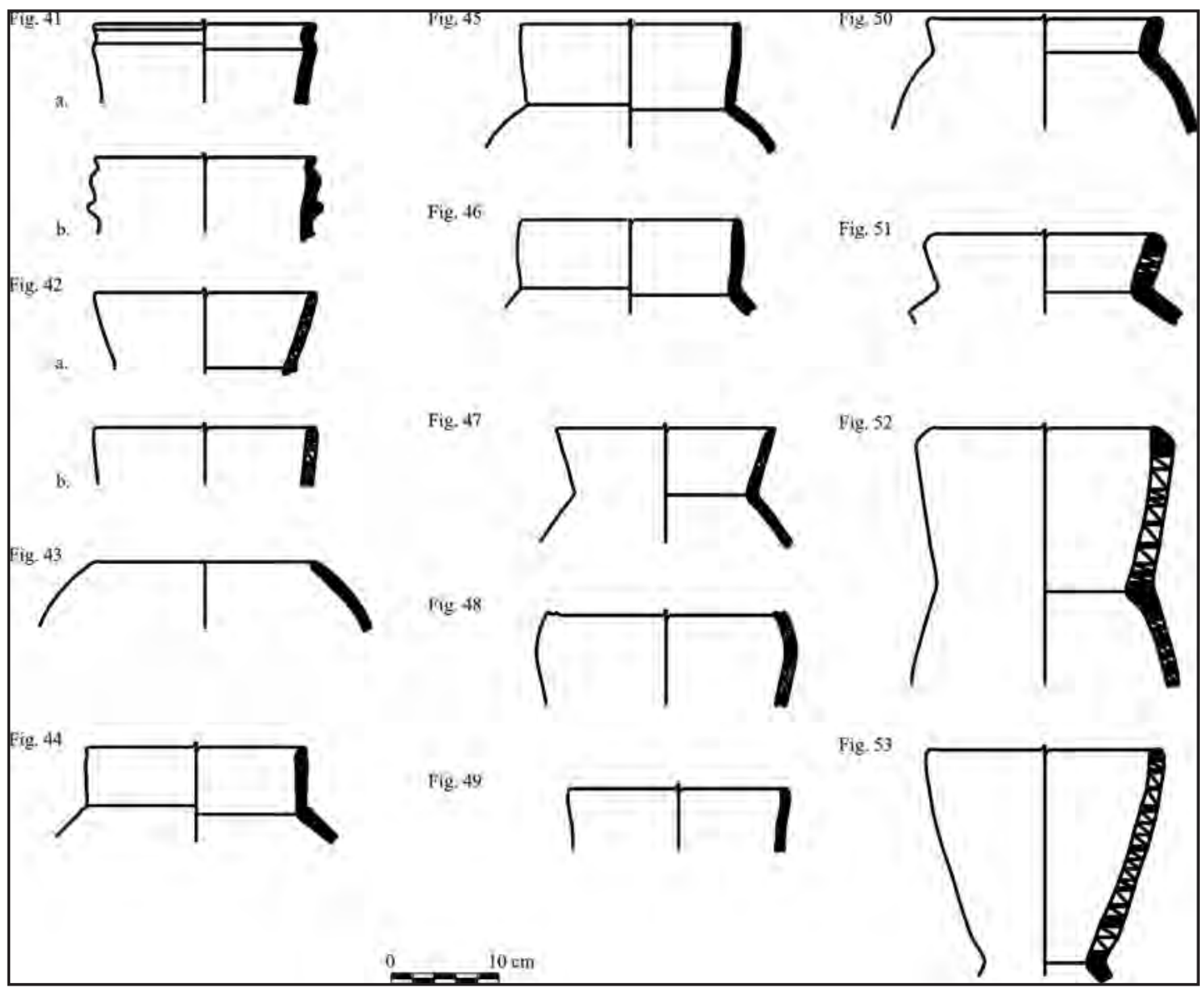

res en posición horizontal, colocadas cerca del labio. (Fig. 54c).

Variante 3: Muestra un fuerte biselado en el labio interno, con elevaciones en ambos lados del mismo. (Fig. 54d).

Variante 4: Tiene la elevación en lado externo mientras que al interno se muestra recto. (Fig. 54e).

Variante 5: La elevación externa es mayor formando un labio redondeado. (Fig. 54f).

\section{Forma 24}

Vasija de cuerpo convergente, borde recto, labio recto y evertido, La superficie es con alisado tosco dejando fuertes marcas horizontales a modo de incisiones. Se elabora en pasta A y no presentan decoración, en ninguno de los 11 ejemplos encontrados, tampoco se han encontrado especimenes quemados. (Fig. 55a).

Variante 1: Muestra un cuerpo más globular. (Fig. 55b).

Variante 2: Esta variante tiene el labio menos evertido. (Fig. 55c).

\section{Forma 25}

Vasija de borde directo, labio recto con una elevación. Se les elabora en pasta B, la superficie se trata con alisado tosco con las clásicas líneas horizontales. El diámetro de boca promedia 24 $\mathrm{cm}$. La decoración consta de pintura aplicada 


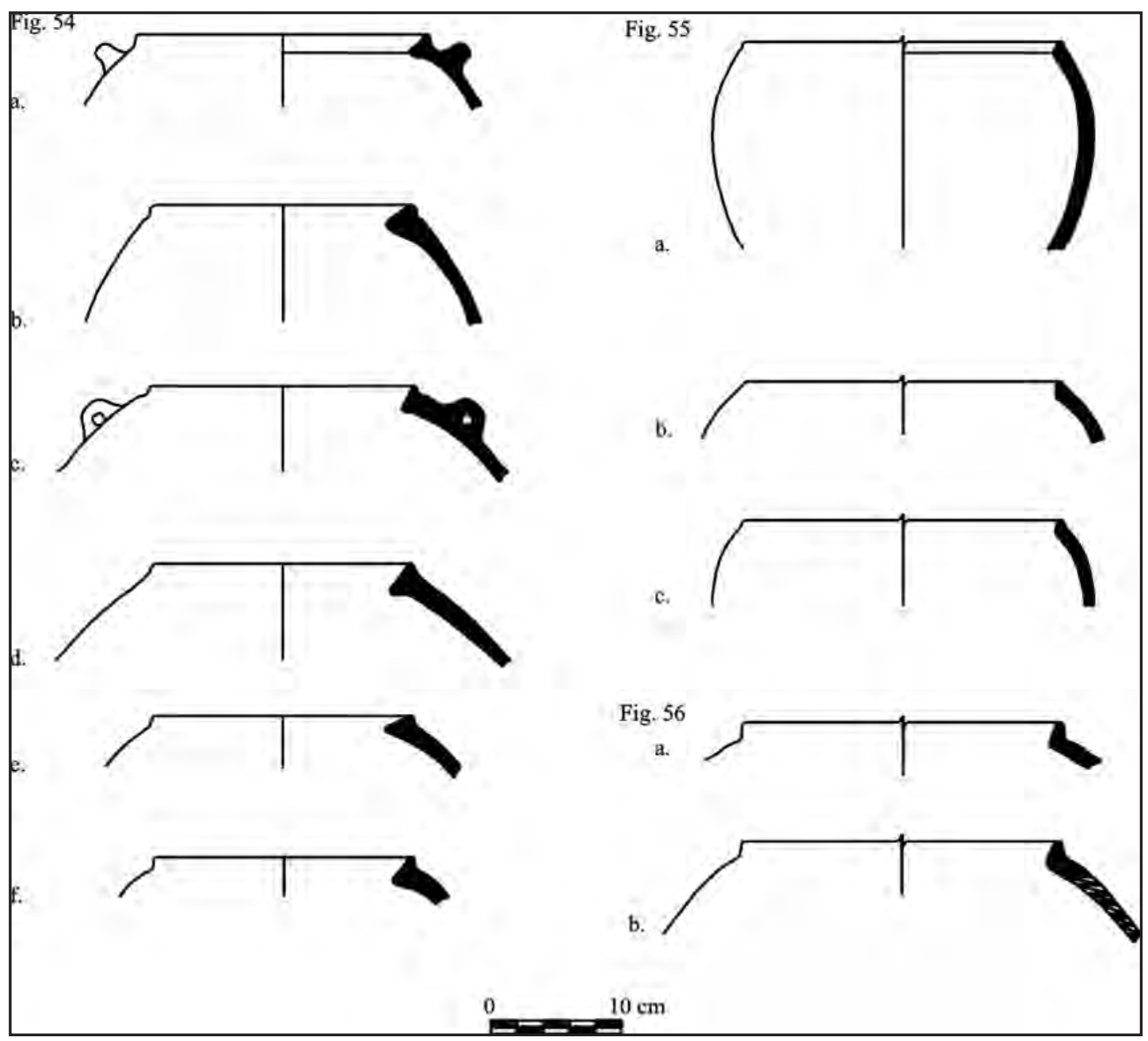

sobre el labio exterior, de manera descuidada. No se encontraron piezas con evidencia de haber sido quemadas. (Fig. 56a).

Variante 1: muestra el labio más redondeado y el cuerpo un poco más redondeado. (Fig. 56b).

\section{Botellas}

\section{Forma 1}

Botella de cuello compuesto y labio redondeado. El borde suele ser engrosado o recto. Se utiliza la pasta B para su fabricación en cocción oxidante, mientras que la superficie es tratada con alisado dejando marcas horizontales en la pared exterior del cuello. La decoración se basa en la aplicación de pintura crema sobre el labio de la vasija. No se encontraron tiestos quemados entre los 3 ejemplares reconocidos. El diámetro de boca promedia los $10 \mathrm{~cm}$. (Fig. 57).

\section{Forma 2}

Botella de cuello compuesto con paredes gruesas y labio adelgazado. Se utiliza la pasta C para su fabricación en cocción oxidante, mientras que la superficie es tratada con alisado dejando marcas horizontales en la pared exterior 

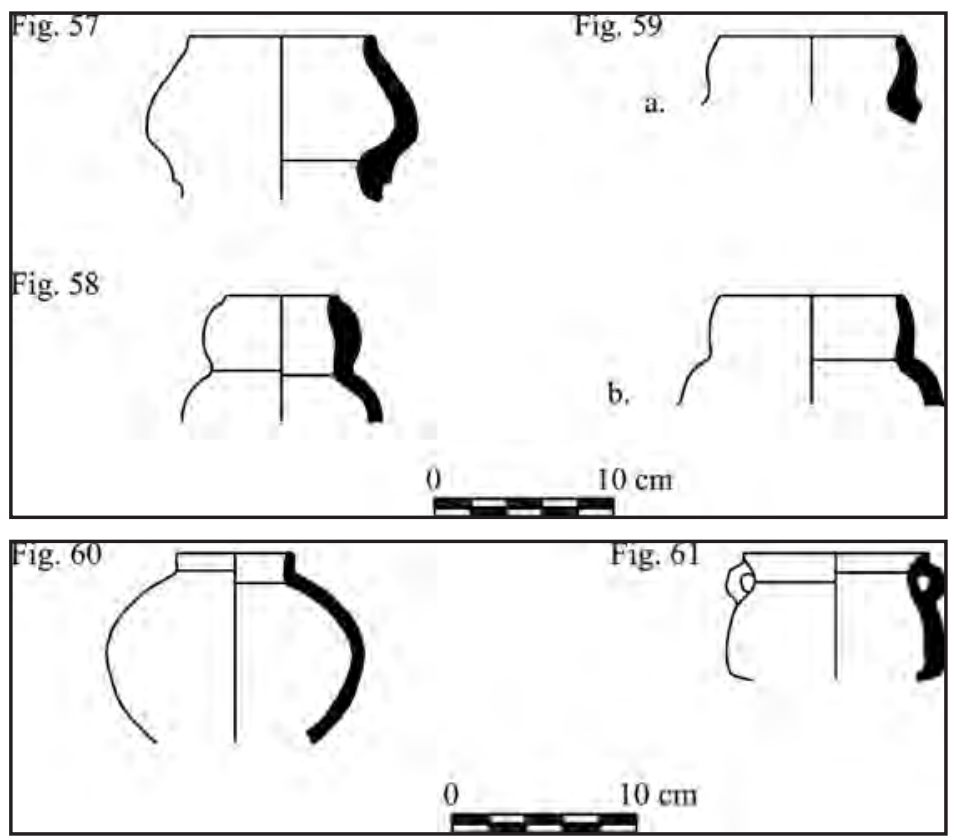

del cuello, sobre todo en la unión con el cuerpo. La decoración se basa en la aplicación de pintura crema sobre el labio de la vasija. No se encontraron tiestos quemados. El diámetro de boca es $6 \mathrm{~cm}$. (Fig. 58).

\section{Forma 3}

Botella de cuello compuesto y labio redondeado. El borde puede ser engrosado o recto, según la variante. Se le fabrica en pasta B y C, para su fabricación en cocción oxidante, mientras que la superficie es tratada con alisado dejando marcas horizontales en la pared exterior del cuello. No se encontraron tiestos quemados. El diámetro de boca es $10 \mathrm{~cm}$. (Fig. 59a).

Variante 1: Presenta el borde recto, sin estar engrosado en su recorrido. (Fig. 59b).

\section{Miniaturas}

\section{Forma 1}

Olla de cuello corto, borde adelgazado y labio redondeado. El cuerpo es globular con base convexa. La pasta utilizada es $B$ mientras que la superficie es alisada. El diámetro de la boca es de $6 \mathrm{~cm}$. No se encontraron piezas decoradas pero sí con evidencias de hollín en la parte externa. (Fig. 60).

\section{Forma 2}

Olla pequeña de cuello corto expandido, labio adelgazado, asas aplicadas uniendo la parte superior del cuerpo con el cuello y cuerpo abombado con base levemente convexa. La pasta utilizada es B. Cocción oxidante, sin decoración, pero sí se observa que la base está quemada, y el diámetro de boca es $10 \mathrm{~cm}$. (Fig. 61).

\section{Decoración}

La decoración para esta fase es también limitada a ciertos elementos sencillos y característicos. Se basa en la aplicación de pintura crema sobre la superficie alisada de la pasta. La pintura es empleada en bandas horizontales en el labio interno y/o externo de la vasija, donde la banda suele promediar $1.5 \mathrm{~cm}$ de ancho; así como en el borde y en la parte baja del cuello donde las bandas de pintura cuando están presentes se encuentran en líneas horizontales de hasta $4 \mathrm{~cm}$ de ancho. (Fig. 62). La pintura crema también es aplicada sobre el cuerpo junto a la unión superior con las asas formando una media luna con la abertura hacia abajo, así como una circunferencia completa en la base del asa. Las líneas verticales son menos frecuentes y suelen partir desde la unión del cuerpo y cuello hacia el punto de tangencia vertical. La decoración con pintura es realizada generalmente de manera descuidada, con trazos irregulares en tamaño y consistencia de la pintura, es muy frecuente encontrar gotas de pintura y trazos chorreados producto del descuido en la elaboración. La pintura crema también es utilizada para cubrir grandes zonas de la vasija, aplicándola muy diluida sobre la superficie cerámica, formando manchas en el cuerpo o el cuello. La pintura 


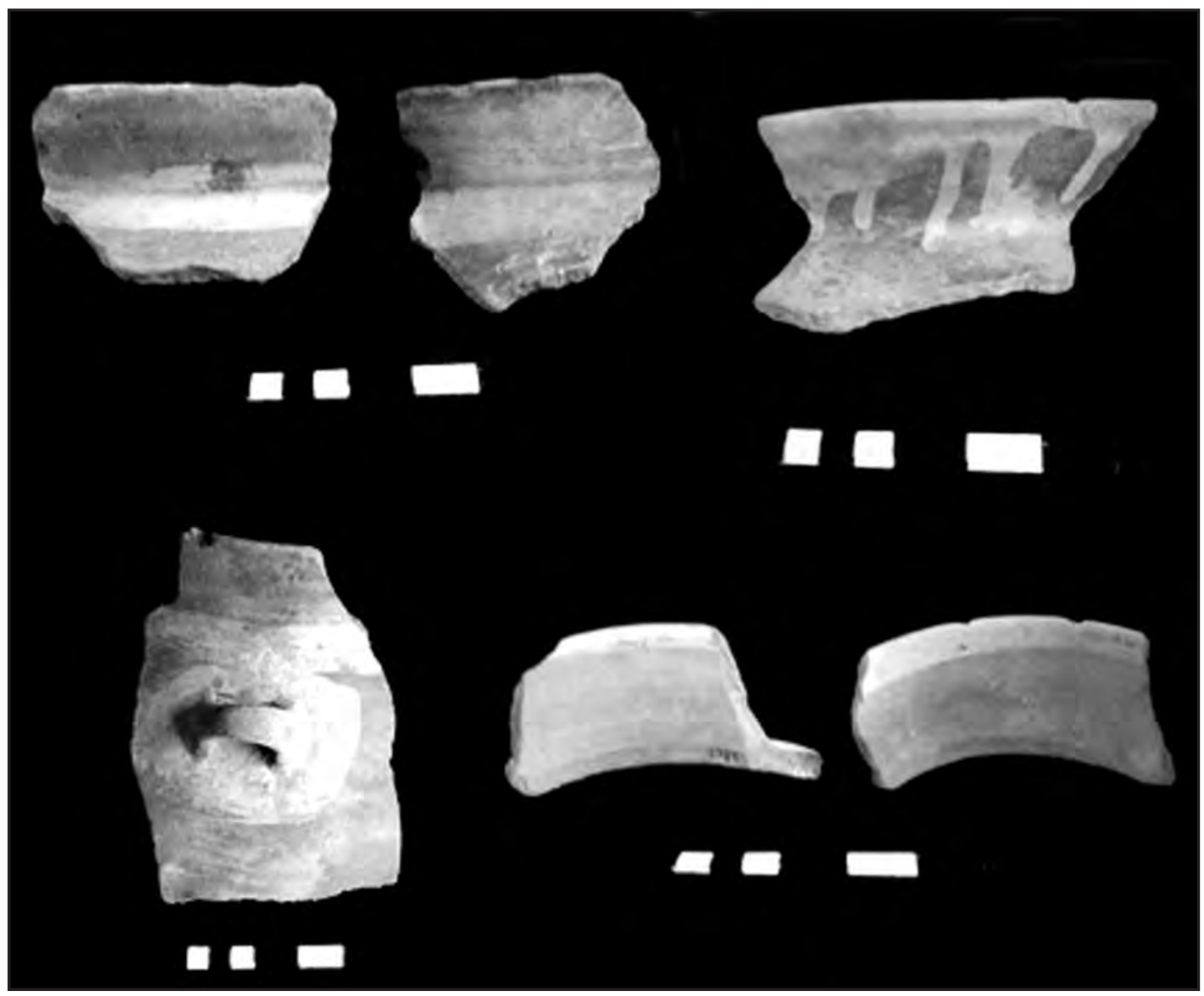

Fig. 62 Decoración con pintura crema chorrada.

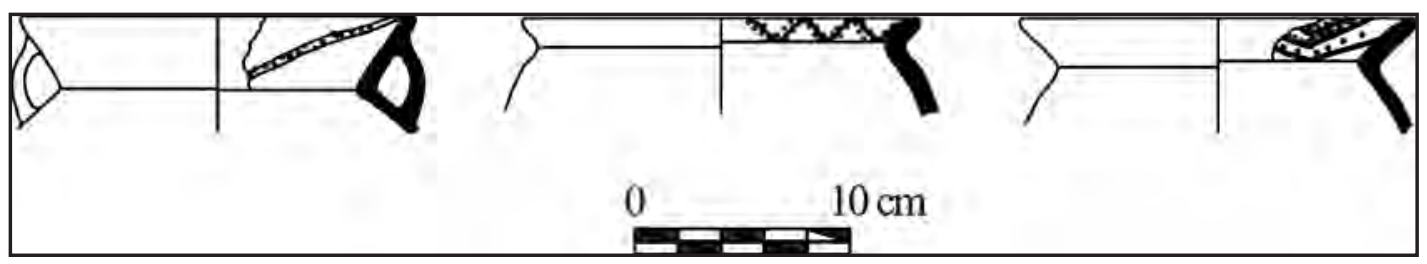

Figura 6. Decoración punteado en zona.

crema también se usa como base para recibir el trazo de líneas negra delgadas de entre 4 y $5 \mathrm{~mm}$ de espesor, que forman diseños geométricos sencillos. El crema y negro pueden aplicarse o no sobre una superficie previamente preparada de color guinda, que también es muy diluida y se observa irregular en la vasija.

Otro tipo de decoración observada, consiste en el denominado punteado en zona, Se presenta demarcando campos en la superficie interna del cuello, a través de líneas incisas profundas, la demarcación forma un diseño en zigzag con una, dos o más líneas en cuyos intermedios se realiza un punteado profundo con algún objeto puntiagudo. Sólo se han encontrado tres tiestos con estas características. (Fig. 63). 


\begin{tabular}{|c|c|c|}
\hline YCHSMA TEMPRANO & YCHSMA MEDIO & YCHSMA TARDIO \\
\hline $\begin{array}{l}\text { Cuellos redondeados y con- } \\
\text { vexos }\end{array}$ & $\begin{array}{l}\text { Pasta más o menos homogé- } \\
\text { neas con un tipo especial para } \\
\text { vasijas grandes }\end{array}$ & $\begin{array}{l}\text { Nuevos tipos de inclusiones en } \\
\text { la pasta anaranjada }\end{array}$ \\
\hline $\begin{array}{l}\text { Asas cintadas en forma ovala- } \\
\text { da entre el cuello y cuerpo. }\end{array}$ & $\begin{array}{l}\text { Labios redondeados y/o adel- } \\
\text { gazados hacia el exterior, con } \\
\text { pocos biselados. }\end{array}$ & $\begin{array}{l}\text { Tendencia a labios aplanados } \\
\text { y/o fuertemente biselados al } \\
\text { exterior. }\end{array}$ \\
\hline $\begin{array}{l}\text { Pintura blanca, negra y roja } \\
\text { aplicada en el tercio superior } \\
\text { de la vasija. }\end{array}$ & $\begin{array}{l}\text { Bandas de pintura blanca cho- } \\
\text { rreada en labios y hombro, so- } \\
\text { bre la pasta sin engobe. }\end{array}$ & $\begin{array}{l}\text { Bandas blancas verticales más } \\
\text { ordenadas y bastante anchas } \\
\text { sobre un engobe rojo }\end{array}$ \\
\hline $\begin{array}{l}\text { Acabado mate con huellas de } \\
\text { imperfección. }\end{array}$ & $\begin{array}{l}\text { Escaso uso de engobe guinda } \\
\text { muy diluido. }\end{array}$ & Engobe guinda casi púrpura. \\
\hline $\begin{array}{l}\text { Presencia de botella de cuerpo } \\
\text { doble. }\end{array}$ & $\begin{array}{l}\text { Ausencia de cerámica negra, } \\
\text { decoración con puntos incisos } \\
\text { dentro de campos geométri- } \\
\text { cos. }\end{array}$ & $\begin{array}{l}\text { Aumento de la cerámica negra. } \\
\text { Decoración incisa de diseños } \\
\text { geométricos pintados después } \\
\text { de la cocción. }\end{array}$ \\
\hline $\begin{array}{l}\text { Decoración con bandas obli- } \\
\text { cuas alternadas con puntos ne- } \\
\text { gros o blancos. }\end{array}$ & $\begin{array}{l}\text { Decoración con pintura crema } \\
\text { en media luna, colocada en el } \\
\text { cuerpo de la vasija, y líneas } \\
\text { cremas delimitadas por pintura } \\
\text { negra. }\end{array}$ & $\begin{array}{l}\text { Serpientes pareadas moldea- } \\
\text { das horizontales sobre el cuer- } \\
\text { po superior y/o el cuello de la } \\
\text { vasija. }\end{array}$ \\
\hline $\begin{array}{l}\text { Formas modeladas ubicadas en } \\
\text { el tercio superior del cuerpo. }\end{array}$ & $\begin{array}{l}\text { Ausencia de la decoración con } \\
\text { serpientes ondulantes. }\end{array}$ & $\begin{array}{l}\text { Batracios modelados de forma } \\
\text { que aparecen agarrados al bor- } \\
\text { de mismo del cuello. }\end{array}$ \\
\hline Uso de platos y cuencos & Ausencia de platos y cuencos & $\begin{array}{l}\text { Otros apéndices zoomorfos que } \\
\text { siempre están colocados en el } \\
\text { borde mismo de la vasija. }\end{array}$ \\
\hline
\end{tabular}

\section{CONCLUSIONES}

La cerámica de Armatambo presenta formas sencillas y decorados sencillos. Las formas cerámicas identificadas en Armatambo corresponden básicamente a vasijas utilitarias como ollas $(57.6 \%)$, cántaros $(16.37 \%)$, tinajas $(27.47 \%)$, botellas (1.18\%) y miniaturas (1.38\%), cabe señalar que las tinajas muestran la mayor variabilidad con 25 formas con sus respectivas variantes, mientras que las ollas y cántaros tienen 15 y 14 respectivamente. En cuanto a formas escultóricas no se podido identificar ningún elemento de este tipo en el estrato de basural arqueológico trabajado.

Los fragmentos decorados con pintura crema alcanzan solo el $12.62 \%$ del total, en tanto el punteado en zona tiene un escaso $0.6 \%$ de representatividad, por otro lado se nota un 
dominio absoluto del alisado como acabado de superficie, el cual suele dejar algunas huellas horizontales y uniformes sobre todo en los cuellos de las vasijas. El análisis de pastas refleja la preferencia en el uso de la pasta B para elaborar indistintamente todos los tipos de vasijas, en cambio la pasta D es preferida para las tinajas de paredes gruesas y aspecto macizo, mientras que la pasta $\mathrm{F}$ se utiliza exclusivamente en un tipo de olla.

$\mathrm{Al}$ realizar una comparación con el material cerámico recuperado en otros sitios del valle del Rímac durante el periodo Intermedio Tardío, encontramos que formas similares ha sido identificadas en Las Palmas, por ejemplo la forma 13 (Fig. 15) es similar una olla del Las Palmas Guinda, (Paredes y Ramos ...:51, fig. 10a), asimismo, forma 1 (fig. 3c) se asemeja a la figura 23a del tipo Crema Restregado y la forma 8 (fig 10) es coherente con la fig 23i del mismo tipo.

Para Cajamarquilla, Narváez (2005) presenta algunos ejemplos que se relacionan con la cerámica de Armatambo, tenemos forma 2 (fig. 4) similar a la fig. 235 de las vasijas Ychsma de la colección Sestieri del Museo de Sitio Arturo Jiménez Borja Puruchuco; el tipo de cuello de botella forma 1 (fig. 57) podría ser una variante de cantaros 245, 246, 247; mientras que la olla forma 4 (fig. 6) se parece a la olla de la figura 117 publicada por Narváez.

Ravines (2003), publica una extensa relación de láminas de fragmentos cerámicos provenientes de Canto Chico, en la margen derecha del río Rímac, lamentablemente el material proviene de contextos disturbados, comparando el material de Canto Chico con el obtenido en Armatambo, encontramos un mayor rango de similitudes, por ejemplo, la forma 1 (fig. 3) corresponde al 3809 de Canto Chico, la forma
7 (fig. 9b) es similar al 4697, la forma 10 (fig. 12a) es la 4960; en cuanto a las tinajas, la forma 23 (fig. 54) es coherente con 1699, 1725, 874, 2010.

La fase Ychsma Medio en Armatambo muestra un rango de particularidades que lo hacen diferenciable del Ychsma Temprano e Ychsma Tardío, analizando las características de las diferentes fases ${ }^{1}$, hemos elaborado el siguiente cuadro que sintetiza las diferencias encontradas.

\section{Bibliografía}

Bazán Del Campo, Francisco

1990 Arqueología y etnohistoria de los Periodos Prehispánicos Tardíos de la Costa Central del Perú. Tesis para optar al Título Profesional de Licenciado en Arqueología. Universidad Nacional Mayor de San Marcos. Lima.

Bueno, Alberto

1982 El Antiguo Valle de Pachacamac. Espacio Tiempo y Cultura. En: Boletín de Lima $\mathrm{N}^{\circ} 24$. pp. 10-29. Lima.

Díaz, Luisa

2000 Informe del Proyecto Arqueológico de Rescate "Asentamiento humano San Pedro"- Armatambo, Chorrillos. Presentado al Instituto Nacional de Cultura, Lima. Manuscrito.

2002 Informe del Proyecto Arqueológico de Rescate "La Rinconada". Presentado al Instituto Nacional de Cultura, Lima. Manuscrito.

2004a Variaciones culturales en el valle de Lima durante la Ocupación Incaica. En: Cuadernos del $51^{\circ}$ Congreso de Americanistas. Chile

\footnotetext{
1 El campo Ychsma Medio del cuadro es producto de la propuesta de Vallejo (2005), el campo Ychsma Tardío condensa las propuestas de Vallejo (2005) y Feltham y Eeckhout (2005), mientras que el campo Ychsma Medio es propuesta del autor.
} 

Caracterizacion de la cerámica de la fase Ychsma Medio...

2004b Informe Final del Proyecto de Rescate Arqueológico A.H. 22 de Octubre Armatambo, Chorrillos. Manuscrito.

2005 Armatambo y la Sociedad Ychsma. En: Boletín del Instituo Francés de Estudios Andinos. $\mathrm{N}^{\circ} 33$ pp. 571-594. Lima.

Díaz, L. y F. Vallejo

2002 Identificación de contextos Ichma en Armatambo. En: Arqueología y Sociedad 14, pp. 47-75, Lima.

2003 Hallazgo de Pirámides con Rampa en Armatambo. En: Medio de Construcción 175, pp. 49-54, Lima.

Feltham, Jane y Peter Eeckhout

2005 Hacia una definición del estilo Ychsma: Aportes preliminares sobre la cerámica Ychsma Tardía de la Prirámide III de Pachacamac. En: Boletín del Instituto Francés de Estudios Andinos. $\mathrm{N}^{\circ}$ 33. pp. 643-679. Lima.

Franco, Régulo

1998 La Pirámide con Rampa N II de Pachacamac. Excavaciones y nuevas interpretaciones. Revista del Museo de Arqueología Trujillo. P 105 Trujillo.

Hyslop, John y Elías Mujica

1992 Investigaciones de A. F. Bandelier en Armatambo (Surco). En: Gaceta Arqueológica Andina 22, pp.63-86. INDEA. Lima.

Iriarte, Brenner

1960 Algunas apreciaciones sobre los huanchos. En: Antiguo Perú; Espacio y tiempo. (Matos, R., ed.) Editoral Juan Mejía Baca. Lima

Paredes, P. y J. Ramos

1994 Excavaciones arqueológicas en el sector Las Palmas, Pachacamac. En:
Boletín de Lima. $\mathrm{N}^{\circ}$ 16. pp. 57-71. Lima

Perez, Maritza

1997 Informe final del proyecto arqueológico en la modalidad de rescate "Héroes del Pacífico". Lima I.N.C. Manuscrito.

Ravines, Rogger.

2003 Canto Chico. Asentamiento prehipánico del Valle del Rímac. En: Boletín de Lima. Vol.XXII. № 119-122 (22).93-294.

Narváez, Joaquín.

2005 Sociedades de la antigua ciudad de Cajamarquilla: Investigaciones arqueológicas en el sector XI del conjunto Tello y un estudio de la colección tardía del conjunto Sestieri.

Rostworowski, M.

1977 Breve ensayo sobre el Señorío de Ychma, etnía y sociedad. Costa Peruana Prehispánica, pp. 197-210, IEP, Lima.

1978 Los Señoríos indígenas de Lima y Canta. Instituto de Estudios Peruanos, Lima.

1999 El Señorío de Pachacamac, el informe de Rodrigo Cantos de Andrade de 1573, Banco Central de Reserva / Instituto de Estudios Peruanos, Lima.

Ruales, M., W. Tosso y F. Vallejo

1983 Informe de las excavaciones de rescate del sector D1 de Armatambo (1983). Informe técnico presentado al Instituto Nacional de Cultura, Lima. Manuscrito.

Salvin, Hugh

1973 (1824) "Diario del Perú". En: Relaciones de Viajeros. Vol. 4으. pp.1-128. Colección Documental de la Independencia del Perú, Lima 
Tello, J. C.

1999 Arqueología del valle de Lima. Cuadernos de Investigación del Archivo Tello, 138 pp. Lima.

Uhle, M.

1903 Pachacamac. Peruvian Expedition of 1896. Department of Archaeology, University of Pennsylvania, Philadelphia.

Vallejo, Francisco.

1998 Secuencia cronológica en base a la cerámica Ichma, En: Separata del Primer Coloquio de Arqueología del Valle del Rímac durante el Periodo Intermedio Tardio, Instituto Nacional de Cultura - Museo de Puruchuco, Lima.
2005 El Estilo Ychsma: Características Generales, Secuencia y Distribución Geográfica. En: Boletín del Instituto Francés de Estudios Andinos. N ${ }^{\circ} 33$. pp. 595-642. Lima.

Villar Córdova, Pedro.

1935 Las Culturas prehispánicas del Departamento de Lima. 